\title{
FORMAÇÃO E CONHECIMENTO: PERSPECTIVAS FILOSÓFICAS E SOCIOLÓGICAS
}

\author{
Carlos Roberto Jamil CurY*
}

Recebido: 3 jun. 2014

Aprovado: 31 jul. 2014

*Pontifícia Universidade Católica de Minas Gerais. Belo Horizonte, MG, Brasil. E-mail: crjcury.bh@terra. com.br

Resumo: O sistema de educação superior no Brasil vem conhecendo grandes deslocamentos e mudanças desde os anos noventa do milênio passado. A legislação federal, mais flexível do que antes, estabeleceu critérios módicos para a abertura de instituições de ensino superior. Ao mesmo tempo, as políticas educacionais depuseram na avaliação de desempenho dos estudantes toda confiança em uma regulamentação das instituições. A publicização de tais resultados mais o mercado sinalizariam a qualidade. Assim, entre 1998 e 2004, a expansão das instituições privadas de ensino superior foi enorme. A legislação posterior buscou regular este processo, sem grande sucesso, já que as instituições privadas passaram a se reger por processos de financeirização e oligopolização, resultando em enormes conglomerados financeiros mais do que educacionais. Paralelamente, houve uma modesta expansão do ensino público e mesmo o apoio do governo para a ocupação de vagas no sistema privado. $\mathrm{O}$ impacto sobre a solidez dos conhecimentos e das práticas que deveriam fazer jus aos princípios estabelecidos na legislação cede o passo para uma mercadorização preocupante.

Palavras-chave: Educação superior no Brasil. Ensino superior e expansão privada. Ensino superior e oligopolização.

\section{KNOWLEDGE AND FORMATION: PHILOSOPHICAL AND SOCIOLOGICAL PERSPECTIVES}

Abstract: The higher education system in Brazil has known great changes and displacements since the Nineties of the past millennium. Our national education law, more flexible than previously, fixed moderated standards to open higher education institutions. At the same time, the educational policies put all the trust in the institutional evaluation and in the performance of the students as form of regulation. The public character of these evaluations and the market would show the institution's quality. So between 1998 and 2004, the increase of the private institutions was enormous. Even a new law of evaluation wasn't able to stop this process. Later legislation tried to regulate this process, since private institutions moved toward oligopolization and opened their capital to stock market investment, resulting in huge conglomerates, more financial than educational in nature. Meanwhile, a modest expansion of public education and governmental support for the occupation of places in the private sector occurred. The impact on the strengthening of knowledge and practices which sustain the principles established in the legislation is subdued by a worrisome commodification.

Key words: Higher Education in Brazil. Higher education and Private Expansion. Higher education and Oligopolization 
A consciência de que educação básica e educação superior fazem parte da organização da educação nacional e agora, graças à emenda n. 59/09 e a lei n. 12.796/13, um sistema nacional de educação, deve levar os responsáveis a não separar em pedaços o que custou tanto para acontecer em nosso ordenamento jurídico. Não é opondo esses dois níveis que ambos sairão melhores.

O Brasil tem dois desafios concomitantes e a resposta a ambos não pode ser dada pela oposição entre os níveis. O desafio da educação básica se impõe pelo resgate de um passado de omissão e por uma situação presente em que esse nível é cada vez mais exigido pela cidadania e pela presença consciente no âmbito da inserção profissional. Aqui, trata-se de sair do anacronismo para se chegar na contemporaneidade.

Já o desafio da educação superior, além da formação profissional pertinente, é o de ser contemporânea no âmbito da ciência e da tecnologia. O domínio da pesquisa básica continua a ser o pilar para um emparelhamento no avanço do conhecimento e sua aplicação tecnológica e a formação não pode ficar sujeita apenas às dimensões pragmáticas de uma inserção profissional.

Vários podem ser, então, os pontos de vista a partir dos quais se pode fazer um exame da Universidade Brasileira a fim de se verificar sua situação no passado, seu estado no presente e sua projeção para o futuro.

Um primeiro comentário que pode ser restritivo quanto ao âmbito de aplicabilidade da educação superior é o uso híbrido do termo "Universidade". Na linguagem comum, é tanto universidade a faculdade isolada recém aparecida na cidade, quanto a Universidade Federal de Minas Gerais ou a Universidade Estadual de Campinas. Hibridismo que se acentua quando Centros Universitários passam a fazer uso indiscriminado da sigla Uni.

Desde logo, cumpre acertar esses ponteiros: universidade, centro universitário ou faculdade são espécies do gênero educação superior, conforme o art. 21, II e art. 45 da Lei de Diretrizes e Bases da Educação Nacional. Entretanto, o conceito de Universidade qua talis aparece no art. 207 da Constituição da República de 1988 e estava presente no já revogado art. 60 do Ato das Disposições Constitucionais Transitórias. Esse art. 207 da Constituição se completa tanto com as finalidades da educação superior, postas no art. 43 da LDBEN, quanto, especificamente, se articula com os artigos 52 e 53 da LDBEN que conceituam e explicitam o grau máximo da educação superior: universidade. E mais, os artigos 55, 56 e 57 da LDBEN se reportam especificamente à universidade pública. Uma prospectiva da formação e do conhecimento não pode ignorar, retrospectivamente, o passado da educação superior no Brasil 
a fim de estabelecer sua diferenciação com os contornos atuais. ${ }^{1}$ Para tanto, este trabalho apoiar-se-á em Rossato (2008) cujo livro descreve e analisa os modelos de universidade, a fim de apontar, nos contornos atuais a que modelo a atual educação superior vem se traduzindo.

\section{UM BALANÇO DO PASSADO PELO PONTO DE VISTA LEGAL}

Não é privilégio da Constituição da República de 1988 o ter inserido em seu texto a figura de Universidade. Seu diferencial está em tê-la conceituado. Pois, a Constituição Imperial de 1824, no art. 179, XXXIII a faz comparecer em seu texto. Já o Ato Adicional de 1834, no seu art. 10, se refere à Faculdade (de Medicina), Cursos Jurídicos e Academias como pertencentes ao ensino superior e sob a jurisdição dos poderes centrais gerais.

A primeira Constituição Republicana (1891) se refere, no art. 34, inciso 30 também a Ensino Superior e, no art. $35, \S 3^{\circ}$ a instituições de ensino superior.

A Constituição de 1934, além de atribuir à União as diretrizes da educação nacional (art. $5^{\circ}$ ), introduz no texto (art. 10, VI) que a difusão da instrução pública em todos os seus graus é competência concorrente entre a União e os Estados. E, no art. 150 letra d, diz ser competência própria da União manter no Distrito Federal...ensino superior e universitário.

A outorgada Constituição de 1937 se serve do termo graus ao falar, no art. 129, de institutos públicos de ensino em todos os seus graus.

A Constituição de 1946 mantém o termo ensino superior, no art. 168, ao remeter-se aos princípios norteadores da legislação. E inova quando, no art. 174, § único diz: a lei promoverá a criação de institutos de pesquisa, de preferência junto aos estabelecimentos de ensino superior. Essa referência à pesquisa comparece em 1967, cuja Constituição dispõe, no § único do art. 171, que o Poder Público incentivará a pesquisa científica e tecnológica. E, no art. $168, \S 3^{\circ}$, III adota a expressão ensino de grau superior. A emenda da Junta Militar em 1969, no art. 176, $\S 3^{\circ}$, introduz ao lado de grau (inciso VI) o termo nivel (inciso III).

Vê-se que o termo Universidade aparece de modo restrito e, quando ele aparece, ganha uma distinção em relação a outras espécies de educação superior, Os termos graus, níveis supõem uma escala que, ao fim e ao cabo, significam a existência de pontos distintos e variados dentro de uma gradação segundo uma ordem de importância crescente ou decrescente.

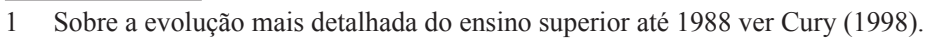


O importante é registrar que a educação superior, em suas distinções específicas, será também objeto do ordenamento infra-constitucional.

No Império, o Decreto n. 7.247/1879, na chamada Reforma Leôncio de Carvalho, refere-se a Faculdades de Direito e de Medicina e à Escola Politécnica. $\mathrm{O}$ art. 20 do Decreto distingue, sem maiores explicações, escola e faculdade no interior da Instrução Superior. E o art. 21 permite a abertura do ensino privado superior. Mas deixa claro que o poder público é o detentor do monopólio do valor oficial a ser atribuído aos graus acadêmicos (diplomas).

$\mathrm{Na}$ Velha República, houve 5 Decretos que acompanharam as diferentes Reformas que se sucederam.

O Decreto n. 1.159/1892, de Fernando Lobo que trata da Instrução Pública Superior e dos Institutos de Ensino Superior. Aqui se explicita, para o ensino privado, o instituto da equiparação. Os Institutos de Ensino Superior e as Faculdades que quisessem se equiparar aos Institutos e Faculdades oficiais deveriam se adequar às exigências estabelecidas nas reformas. Dentre as exigências, a primeira delas era a Inspeção, conditio sine qua non para posterior obtenção do título de Estabelecimento Equiparado. Se preenchidas as condições, esse estabelecimento poderia obter as credenciais próprias do reconhecimento e, então, exarar diplomas, conceder títulos, dignidades e outras atribuições de estabelecimento equiparado.

No Decreto n. 3.890/1901, de Epitácio Pessoa mantém-se a expressão Ensino Superior.

O Decreto n. 8.659/1911 de Rivadávia Corrêa, desoficializando o ensino superior, introduz o Conselho Superior de Ensino e o exame de admissão para esse ensino (vestibular). Por meio dela, o governo do presidente Hermes da Fonseca, tendo como seu ministro da Justiça o jurista Rivadávia Corrêa, ambos seguidores da doutrina positivista, buscaram o fim do status oficial do ensino. Baseando-se em uma interpretação discutível de um artigo da Constituição de 1891, o governo, por meio de um decreto presidencial, apoiado pelos parlamentares, determinou que as escolas de ensino secundário e de ensino superior perderiam os seus status de oficial e passariam a ser entidades corporativas autônomas. Com isso o Estado perde a titularidade do monopólio da validade oficial dos diplomas e certificados e tal prerrogativa passa a ser dessas entidades. $\mathrm{O}$ ensino livre seria o remédio para os considerados maus catedráticos, para a contenção desenfreada de diplomas, de fraudes e de instalações precárias dos estabelecimentos. Um Conselho Superior de Ensino 
seria como que uma espécie das atuais Agências Reguladoras como órgão máximo da administração federal da educação. ${ }^{2}$

O Decreto n. 11.530/1915 de Carlos Maximiliano reoficializa o ensino superior em vista dos problemas advindos da expansão desenfreada e sem controle de institutos particulares. Em seu texto se lê: quando achar oportuno, o governo poderá reunir os institutos federais no Rio de Janeiro sob a figura de Universidade. Contudo, escolas, academias ou faculdades só poderiam ser criadas em cidades com mais de 100 mil habitantes e nas capitais dos Estados.

O Decreto n. 16.782/1925 de João Alves/Rocha Vaz cria o Conselho Nacional de Ensino e o Departamento Nacional do Ensino aos quais caberiam conceder ou não a concessão de abertura de escolas de educação superior e equiparar as não estatais. O Decreto n. 5.616 de 1928 regula a criação de Universidades nos Estados.

O que se pode inferir destas instituições, de seus currículos e de seus egressos, é que elas podem ser classificadas dentro de um modelo misto de ensino superior, cruzando o ensino da universidade newtoniana com a preparação de quadros burocráticos e profissionais do modelo napoleônico. ${ }^{3}$ Obviamente, elas não cultivavam a pesquisa.

Com a Revolução de Trinta, sob Decreto n. 19.402 de 14 de novembro de 1930, nascia no Brasil, uma Secretaria de Estado sob a denominação de Ministério dos Negócios da Educação e Saúde Pública. O Governo Provisório de Vargas criou o Conselho Nacional de Educação (Decreto n. 19.850/1931) e sob o Decreto n. 19.851 de 1931 institui o Estatuto das Universidades, distingue um sistema universitário dos institutos isolados. O sistema universitário teria que ter um padrão único de referência no qual se impunha a investigação cientifica em quaisquer domínios dos conhecimentos humanos (art. 1o.) como sua finalidade. Esse ensino deveria estimular o espírito de investigação original, indispensável ao progresso das ciências.

Aqui, embora questionável do ponto de vista de sua efetividade, propunha-se um modelo de universidade humboldtiana.

Durante a ditadura Vargas é de se apontar o Decreto-Lei n. 421 de 1938 que regulava o funcionamento dos estabelecimentos de Ensino Superior, a autorização de funcionamento e o reconhecimento dos estabelecimentos.

Com o processo de redemocratização, entre 1946 e 1964, algumas iniciativas se tornam importantes. A Lei n. 1.254/1950 dispõe, no sistema federal de ensino superior, a categoria de estabelecimentos diretamente mantidos pela

2 Sobre esta desoficialização ver Cury (2009).

3 Sobre os modelos de universidade ver Rossato (2008) e Araujo (2011). 
União e o sistema supletivo dos sistemas estaduais. Essa mesma lei abre a possibilidade para a federalização de outras instituições de ensino superior nos Estados. No ano subsequente há a criação do CNPq (lei n. 1.310 de janeiro de 1951) e da CAPES (Decreto n. 29.741 de 11/06/1951).

Sob o regime parlamentarista, em 1961, após 13 anos de tramitação, é aprovada a lei n. 4.024/61. O artigo 80 dessa mesma lei dispõe: "As universidades gozarão de autonomia didática, administrativa, financeira e disciplinar que será exercida na forma de seus estatutos".

Ao mesmo tempo, essa lei instituiu o Conselho Federal de Educação (CFE) ao qual ficou atribuída, entre outras competências, a decisão "sobre o funcionamento dos estabelecimentos isolados de ensino superior, federais e particulares (letra a do art. $9^{\circ}$ ), decidir sobre o reconhecimento das universidades mediante a aprovação de seus estatutos". (letra b do art. $9^{\circ}$ ). Essa letra b dependia, pelo $\S 1^{\circ}$ do mesmo artigo, da homologo ministerial.

A lei n. 4.024/61 com a redação dada pela lei n. 5.540/68 trará modificações tão significativas na educação superior que dela se pode dizer ter sido uma lei de reforma universitária.

Face ao modelo existente, a rigor vindo do Estatuto de 1931, ela instituirá os distritos geoeducacionais, extinguirá a cátedra, criará os departamentos/ colegiados, o ciclo básico, os institutos, o regime de dedicação exclusiva e o modelo preferencial da educação superior como Universidade.

A Reforma Universitária de 1968, lei n. 5.540, em que houve toda uma configuração nova a partir da associação entre ensino, pesquisa trazia em seus 3 primeiros artigos o seguinte:

Art. $1^{\circ} \mathrm{O}$ ensino superior tem por objetivo a pesquisa, o desenvolvimento das ciências, letras e artes e a formação de profissionais de nível universitário.

Art. $2^{\circ} \mathrm{O}$ ensino superior, indissociável da pesquisa, será ministrado em universidades e, excepcionalmente, em estabelecimentos isolados, organizados como instituições de direito público ou privado.

Art. $3^{\circ}$ As universidades gozarão de autonomia didático-científica, disciplinar, administrativa e financeira, que será exercida na forma da lei e dos seus estatutos.

Pode-se dizer que, apesar dos controles exercidos pela ditadura militar, o modelo que passou a se efetivar, inclusive com a sistematização da pós-graduação, foi o modelo humboldtiano. 
A partir daí, a passagem desse princípio ao modus operandi em regras mais próximas da vida universitária conheceria muitas idas e vindas, especialmente no sentido da aplicação da autonomia e seu âmbito de aplicabilidade. Também se deve apontar, como se verá, o papel estratégico exercido pelo CFE via Pareceres e Resoluções. O Conselho Federal de Educação, dotado de poderes, fará exarar importantes pareceres como o Parecer n. 977/65 que institucionalizou pós-graduação no Brasil (CURY, 2005).

Vários foram os dispositivos durante a ditadura que, de um lado, reprimiram iniciativas e, de outro lado, buscaram a institucionalização da universidade (CUNHA, 1988).

No início dos anos 80, o Programa de Avaliação da Reforma Universitária de 1968 (PARU), introduz a temática da avaliação nas universidades, apesar de não ter havido prosseguimento do processo avaliativo. O governo da denominada "Nova República", pretendendo recolocar a Universidade como parceira na busca de uma nova legitimidade, cria a "Comissão Nacional para a R0065formulação do Ensino Superior”, da qual resultaria, em 1986, o "Grupo Executivo para a Reformulação da Educação Superior” (GERES). Também desta dinâmica, da qual resultou muito debate sobre os fins da universidade, seu financiamento e avaliação, não houve grandes consequências ${ }^{4}$.

\section{DA CONSTITUIÇÃO DE 1988 AOS DIAS ATUAIS}

A Constituição da República de 1988, em seu artigo 207, conceitua a Universidade como figura autônoma. Pela primeira vez, ela é posta na Lei Maior. Em outras épocas ela era tratada na legislação infraconstitucional. Diz o dispositivo: "As Universidades gozam de autonomia didático-científica. Administrativa e de gestão financeira e patrimonial, e obedecerão ao princípio de indissociabilidade entre ensino, pesquisa e extensão".

Quanto ao ensino privado, posto no art. 209, ele passa do estatuto da concessão para o da autorização, coexistindo com as instituições públicas sob a obediência à autorização de funcionamento, à avaliação de qualidade, à LDB e outras leis de referência pertinentes.

Uma primeira lei de referência será a redação dada à lei n. 4.024/61 com aprovação da lei n. 9.131/95 que regula a avaliação institucional da educação superior e (re)cria o Conselho Nacional de Educação.

A segunda referência forte será a aprovação das diretrizes e bases da educação nacional mediante a lei n. 9.394/96 e todo o capítulo referente à educa-

4 Ver Ristoff (1996), Avaliação (2008). 
ção superior. Esse capítulo sofreu apenas duas alterações em lei, desde 1996: a que modificou o inciso I do art. 44 e, depois, o acréscimo de um $\S$ único. No primeiro caso, exigindo o ensino médio como condição para os cursos sequenciais (lei n. 11.623/07) e, no segundo, a que impôs a publicidade dos resultados do processo seletivo (lei n. 11.331/06).

A terceira referência foi a lei 10.172/2001, do Plano Nacional de Educação do qual constava um capítulo próprio para a educação superior. Sabe-se que, por falta de recursos, este plano fracassou em suas metas, inclusive naquela que postulava para o setor público, no período, uma proporção nunca inferior a $40 \%$.

Contudo, aquilo que mais alterou o capítulo da educação superior foi o conjunto de decretos quase que a ensejar um verdadeiro cipoal legislativo. $\mathrm{O}$ primeiro deles foi o de n. 2207/97 logo revogado pelo de n. 2.306/97. Esse Decreto ao regular o sistema federal de educação, cria a figura dos centros universitários (art. $8^{\circ}$ e 12) e normatiza a figura das entidades privadas com e sem fins lucrativos. Tais decretos foram revogados pelo Decreto n. 3.860/2001, deles o mais completo. Esse Decreto sofreu a revogação do seu art. 11 por meio do Decreto n. 4.914/2003 que extinguia a autonomia dos centros universitários e, em certo sentido, os impelia ou a se tornarem universidades ou a retomar a sua situação anterior. O decreto n. 3.860 acabou sendo revogado, entre outros, pelo enorme e complexo Decreto n. 5.773 de 2006. Esse último, contudo, mantinha o Decreto n. 4.914/03 e cujo teor, finalmente, foi revogado pelo Decreto n. 5.786/2006 que repõe a autonomia dos Centros Universitários.

Em parte, o volume de artigos do Decreto n. 5.773/06 se deveu à lei n. 10.861/2004 que criou o Sistema Nacional de Avaliação da Educação Superior (SINAES) que revogou a alínea a do $\S 2^{\circ}$ do art. $9^{\circ}$ da Lei $n^{\circ} 4.024$, de 20 de dezembro de 1961 , e os arts. $3^{\circ}$ e $4^{\circ}$ da Lei $n^{\circ} 9.131$, de 24 de novembro de 1995, pondo fim ao sistema de avaliação conhecido como Provão (a rigor: Exame Nacional de Cursos). O art. $7^{\circ}$ dessa lei prevê uma Comissão Nacional de Avaliação da Educação Superior (CONAES), o que se deu por meio do Decreto n. 5.262/2004.

Por outro lado, uma avaliação sem conseqüências se desmoraliza. Uma autorização frouxa traz resultados ruins para todo o processo pois não se pode deixar tudo (quando se deixa) para um pós - avaliação. Nesse caso, o mal pode já ter sido perpetrado na profissionalização de pessoas que terão responsabilidades com os cidadãos.

A regulação pode ser melhor compreendida quando se diz do seu oposto: des-regulação. Ou seja, não há controles e nem medidas para se chegar aos 
fins almejados. Regulação tem a ver com qualidade e com uma qualidade conforme aos fins, princípios e objetivos. A rede privada de ensino superior faz parte do sistema público federal. Daí o art. 209 da Constituição. Não há avaliação de qualidade sem regulação. Mas hoje temos um verdadeiro cipoal no âmbito legal e normativo. Talvez a proposta de um sistema nacional possa gerar mais clareza no aspecto de regulação.

O projeto de lei n. 8.035/2010 contendo o Plano Nacional de Educação, ora em discussão final no Congresso Nacional, traz metas relativas ao ensino superior. São 4 metas e 42 estratégias. A de n. 12 com 16 estratégias, se propõe à elevação das matrículas; a de n. 13 com 7 estratégias almeja a qualidade do ensino pela elevação do número de mestres e de doutores; a de n. 14 com 09 estratégias é a que propõe o aumento de mestrandos e doutorandos e a de $n$. 15 com 10 estratégias se refere à qualificação do corpo docente da educação básica em licenciaturas e na pedagogia.

Ei-las, em sua integralidade:

Meta 12: Elevar a taxa bruta de matrícula na educação superior para cinquenta por cento e a taxa líquida para trinta e três por cento da população de dezoito a vinte e quatro anos,assegurando a qualidade da oferta.

Estratégias:

12.1) Otimizar a capacidade instalada da estrutura física e de recursos humanos das instituições públicas de educação superior, mediante ações planejadas e coordenadas, de forma a ampliar e interiorizar o acesso à graduação.

12.2) Ampliar a oferta de vagas por meio da expansão e interiorização da rede federal de educação superior, da Rede Federal de Educação Profissional, Científica e Tecnológica e do Sistema Universidade Aberta do Brasil, considerando a densidade populacional, a oferta de vagas públicas em relação à população na idade de referência e observadas as características regionais das micro e mesorregiões definidas pela Fundação Instituto Brasileiro de Geografia e Estatística - IBGE, uniformizando a expansão no território nacional. 12.3) Elevar gradualmente a taxa de conclusão média dos cursos de graduação presenciais nas universidades públicas para noventa por cento, ofertar um terço das vagas em cursos noturnos e elevar a relação de estudantes por professor para dezoito, mediante estratégias de aproveitamento de créditos e inovações acadêmicas que valorizem a aquisição de competências de nível superior.

12.4) Fomentar a oferta de educação superior pública e gratuita prioritariamente para a formação de professores para a educação básica, sobretudo nas áreas de ciências e matemática, bem como para atender ao déficit de profissionais em áreas específicas. 
12.5) Ampliar, por meio de programas especiais, as políticas de inclusão e de assistência estudantil nas instituições públicas de educação superior, de modo a ampliar as taxas de acesso à educação superior de estudantes egressos da escola pública, apoiando seu sucesso acadêmico.

12.6) Expandir o financiamento estudantil por meio do Fundo de Financiamento ao Estudante do Ensino Superior - FIES, de que trata a Lei no 10.260 , de 12 de julho de 2001, por meio da constituição de fundo garantidor do financiamento, de forma a dispensar progressivamente a exigência de fiador.

12.7) Assegurar, no mínimo, dez por cento do total de créditos curriculares exigidos para a graduação em programas e projetos de extensão universitária.

12.8) Fomentar a ampliação da oferta de estágio como parte da formação de nível superior.

12.9) Ampliar a participação proporcional de grupos historicamente desfavorecidos na educação superior, inclusive mediante a adoção de políticas afirmativas, na forma da lei.

12.10) Assegurar condições de acessibilidade nas instituições de educação superior, na forma da legislação.

12.11) Fomentar estudos e pesquisas que analisem a necessidade de articulação entre formação, currículo e mundo do trabalho, considerando as necessidades econômicas, sociais e culturais do País.

12.12) Consolidar e ampliar programas e ações de incentivo à mobilidade estudantil e docente em cursos de graduação e pós-graduação, em âmbito nacional e internacional, tendo em vista o enriquecimento da formação de nível superior.

12.13) Expandir atendimento específico a populações do campo e indígena, em relação a acesso,permanência, conclusão e formação de profissionais para atuação junto a estas populações.

12.14) Mapear a demanda e fomentar a oferta de formação de pessoal de nível superior, considerando as necessidades do desenvolvimento do País, a inovação tecnológica e a melhoria da qualidade da educação básica.

12.15) Institucionalizar programa de composição de acervo digital de referências bibliográficas para os cursos de graduação.

12.16) consolidar processos seletivos nacionais e regionais para acesso à educação superior como forma de superar exames vestibulares isolados;

12.17) estimular mecanismos para ocupar as vagas ociosas em cada período letivo na educação superior pública;

12.18) estimular a expansão e reestruturação das instituições de educação superior estaduais e municipais cujo ensino seja gratuito, por meio de apoio técnico e financeiro do Governo Federal, mediante termo de adesão a programa de reestruturação, na forma de regulamento, que considere a sua contribuição para a ampliação de 
vagas, a capacidade fiscal e as necessidades dos sistemas de ensino dos entes mantenedores na oferta e qualidade da educação básica; 12.19) reestruturar com ênfase na melhoria de prazos e qualidade da decisão, no prazo de 2 (dois) anos, os procedimentos adotados na área de avaliação, regulação e supervisão, em relação aos processos de autorização de cursos e instituições, de reconhecimento ou renovação de reconhecimento de cursos superiores e de credenciamento ou recredenciamento de instituições, no âmbito do sistema federal de ensino;

12.20) ampliar, no âmbito do Fundo de Financiamento ao Estudante do Ensino Superior - FIES, de que trata a Lei ${ }^{\circ} 10.260$, de 12 de julho de 2001, e do Programa Universidade para Todos - PROUNI, de que trata a Lei no11.096, de 13 de janeiro de 2005, os benefícios destinados à concessão de financiamento a estudantes regularmente matriculados em cursos superiores presenciais ou a distância, com avaliação positiva, de acordo com regulamentação própria, nos processos conduzidos pelo Ministério da Educação;

12.21) fortalecer as redes físicas de laboratórios multifuncionais das IES e ICTs nas áreas estratégicas definidas pela política e estratégias nacionais de ciência, tecnologia e inovação.

Meta 13: Elevar a qualidade da educação superior pela ampliação da atuação de mestres e doutores nas instituições de educação superior para setenta e cinco por cento, no mínimo, do corpo docente em efetivo exercício, sendo, do total, trinta e cinco por cento doutores.

Estratégias:

13.1) Aprofundar e aperfeiçoar o Sistema Nacional de Avaliação da Educação Superior - SINAES, de que trata a Lei no 10.861, de 14 de abril de 2004, fortalecendo as ações de avaliação, regulação e supervisão.

13.2) Ampliar a cobertura do Exame Nacional de Desempenho de Estudantes - ENADE, de modo a que mais estudantes, de mais áreas, sejam avaliados no que diz respeito à aprendizagem resultante da graduação.

13.3) Induzir processo contínuo de autoavaliação das instituições superiores, fortalecendo a participação das comissões próprias de avaliação, bem como a aplicação de instrumentos de avaliação que orientem as dimensões a serem fortalecidas, destacando-se a qualificação e a dedicação do corpo docente.

13.4) Induzir a melhoria da qualidade dos cursos de pedagogia e licenciaturas, por meio da aplicação de instrumento próprio de avaliação aprovado pela Comissão Nacional de Avaliação da Educação Superior - CONAES, de modo a permitir aos graduandos a aquisição das competências necessárias a conduzir o processo de aprendizagem de seus futuros alunos, combinando formação geral e prática didática. 
13.5) Elevar o padrão de qualidade das universidades, direcionando sua atividade, de modo que realizem, efetivamente, pesquisa institucionalizada, na forma de programas de pósgraduação stricto sensu. 13.6) Substituir o Exame Nacional de Desempenho dos Estudantes - ENADE aplicado ao final do primeiro ano do curso de graduação pelo Exame Nacional do Ensino Médio - ENEM, a fim de apurar o valor agregado dos cursos de graduação.

13.7) Fomentar a formação de consórcios entre universidades públicas de educação superior, com vistas a potencializar a atuação regional, inclusive por meio de plano de desenvolvimento institucional integrado, assegurando maior visibilidade nacional e internacional às atividades de ensino, pesquisa e extensão.

13.8) elevar gradualmente a taxa de conclusão média dos cursos de graduação presenciais nas universidades públicas, de modo a atingir $90 \%$ (noventa por cento) e, nas instituições privadas, $75 \%$ (setenta e cinco por cento), em 2020, e fomentar a melhoria dos resultados de aprendizagem, de modo que, em 5 (cinco) anos, pelo menos 60\% (sessenta por cento) dos estudantes apresentem desempenho positivo igual ou superior a $60 \%$ (sessenta por cento) no Exame Nacional de Desempenho de Estudantes - ENADE e, no último ano de vigência, pelo menos $75 \%$ (setenta e cinco por cento) dos estudantes obtenham desempenho positivo igual ou superior a $75 \%$ (setenta e cinco por cento) nesse exame, em cada área de formação profissional; 13.9) promover a formação inicial e continuada dos (as) profissionais técnico-administrativos da educação superior.

Meta 14: Elevar gradualmente o número de matrículas na pós-graduação stricto sensu, de modo a atingir a titulação anual de sessenta mil mestres e vinte e cinco mil doutores.

Estratégias:

14.1) Expandir o financiamento da pós-graduação stricto sensu por meio das agências oficiais de fomento.

14.2) Estimular a integração e a atuação articulada entre a Coordenação de Aperfeiçoamento de Pessoal de Nível Superior - CAPES, e as agências estaduais de fomento à pesquisa.

14.3) Expandir o financiamento estudantil por meio do FIES à pós-graduação stricto sensu, especialmente ao mestrado profissional.

14.4) Expandir a oferta de cursos de pós-graduação stricto sensu, utilizando metodologias, recursos e tecnologias de educação a distância, inclusive por meio do Sistema Universidade Aberta do Brasil.

14.5) Consolidar programas, projetos e ações que objetivem a internacionalização da pesquisa e da pós-graduação brasileira, incentivando a atuação em rede e o fortalecimento de grupos de pesquisa. 14.6) Promover o intercâmbio científico e tecnológico, nacional e internacional, entre as instituições de ensino, pesquisa e extensão.

14.7) Implementar ações para redução de desigualdades regionais 
e para favorecer o acesso das populações do campo e indígena a programas de mestrado e doutorado.

14.8) Ampliar a oferta de programas de pós-graduação stricto sensu, especialmente o de doutorado, nos campi novos abertos no âmbito dos programas de expansão e interiorização das instituições superiores públicas.

14.9) Manter e expandir programa de acervo digital de referências bibliográficas para os cursos de pós-graduação.

14.10) promover o intercâmbio científico e tecnológico, nacional e internacional, entre as instituições de ensino, pesquisa e extensão; 14.11) ampliar o investimento em pesquisas com foco em desenvolvimento e estímulo à inovação, bem como incrementar a formação de recursos humanos para a inovação, de modo a buscar o aumento da competitividade das empresas de base tecnológica;

14.12) ampliar o investimento na formação de doutores de modo a atingir a proporção de 4 (quatro) doutores por 1.000 (mil) habitantes;

14.13) aumentar qualitativa e quantitativamente o desempenho científico e tecnológico do País e a competitividade internacional da pesquisa brasileira, ampliando a cooperação científica com empresas, Instituições de Educação Superior - IES e demais Instituições Científicas e Tecnológicas - ICTs;

14.14) estimular a pesquisa científica e de inovação e promover a formação de recursos humanos que valorize a diversidade regional e a biodiversidade da região amazônica e do cerrado, bem como a gestão de recursos hídricos no semiárido para mitigação dos efeitos da seca e geração de emprego e renda na região;

14.15) estimular a pesquisa aplicada, no âmbito das IES e das ICTs, de modo a incrementar a inovação e a produção e registro de patentes.

Meta 15: garantir, em regime de colaboração entre a União, os Estados, o Distrito Federal e os Municípios, no prazo de 1 (um) ano de vigência deste PNE, política nacional de formação dos profissionais da educação de que tratam os incisos I, II e III do caput do art. 61 da Lei no 9.394, de 20 de dezembro de 1996, assegurado que todos os professores e as professoras da educação básica possuam formação específica de nível superior, obtida em curso de licenciatura na área de conhecimento em que atuam. Estratégias:

15.1) Atuar conjuntamente, com base em plano estratégico que apresente diagnóstico das necessidades de formação de profissionais do magistério e da capacidade de atendimento por parte de instituições públicas e comunitárias de educação superior existentes nos Estados, Municípios e Distrito Federal, e defina obrigações recíprocas entre os partícipes. 
15.2) Consolidar o financiamento estudantil a estudantes matriculados em cursos de licenciatura com avaliação positiva pelo SINAES, na forma da Lei no 10.861, de 2004, permitindo inclusive a amortização do saldo devedor pela docência efetiva na rede pública de educação básica. 15.3) Ampliar programa permanente de iniciação à docência a estudantes matriculados em cursos de licenciatura, a fim de incentivar a formação de profissionais do magistério para atuar na educação básica pública.

15.4) Consolidar plataforma eletrônica para organizar a oferta e as matrículas em cursos de formação inicial e continuada de professores, bem como para divulgação e atualização dos currículos eletrônicos dos docentes.

15.5) Institucionalizar, no prazo de um ano de vigência do PNE 2011/2020, política nacional de formação e valorização dos profissionais da educação, de forma a ampliar as possibilidades de formação em serviço.

15.6) Implementar programas específicos para formação de professores para as populações do campo, comunidades quilombolas e povos indígenas.

15.7) Promover a reforma curricular dos cursos de licenciatura, de forma a assegurar o foco no aprendizado do estudante, dividindo a carga horária em formação geral, formação na área do saber e didática específica.

15.8) Induzir, por meio das funções de avaliação, regulação e supervisão da educação superior, a plena implementação das respectivas diretrizes curriculares.

15.9) Valorizar o estágio nos cursos de licenciatura, visando trabalho sistemático de conexão entre a formação acadêmica dos graduandos e as demandas da rede pública de educação básica.

15.10) Implementar cursos e programas especiais para assegurar formação específica em sua área de atuação aos docentes com formação de nível médio na modalidade normal, não licenciados ou licenciados em área diversa da de atuação docente, em efetivo exercício.

15.11) implantar, no prazo de 1 (um) ano de vigência desta Lei, política nacional de formação continuada para os (as) profissionais da educação de outros segmentos que não os do magistério, construída em regime de colaboração entre os entes federados;

15.12) instituir programa de concessão de bolsas de estudos para que os professores de idiomas das escolas públicas de educação básica realizem estudos de imersão e aperfeiçoamento nos países que tenham como idioma nativo as línguas que lecionem;

15.13) desenvolver modelos de formação docente para a educação profissional que valorizem a experiência prática, por meio da oferta, nas redes federal e estaduais de educação profissional, de cursos voltados à complementação e certificação didático-pedagógica de profissionais experientes. 
Se colocarmos aí a função normativa, por lei, do Conselho Nacional de Educação por meio de pareceres e resoluções, mais a parte do papel de avaliação do INEP, do INSAES, da SESU sem falar das inúmeras Portarias e interpretações do poder judiciário, então o cipoal se transforma em uma verdadeira façanha para sair do labirinto. Esse emaranhado de leis, decretos, portarias, pareceres, resoluções, decisões judiciais e tudo o mais necessita de um Teseu ajudado pelo fio de Ariadne para decifrar e sair do labirinto do Minotauro...

Além disso, nosso judiciário ainda tem uma cultura do liberalismo clássico em que o direito individual é o ponto hegemônico de sua leitura do real. Por outro lado, há indicações de que jovens juristas presentes no Ministério Público tendem a ler o real também pelo ângulo dos direitos sociais.

De qualquer modo, pode-se afirmar que a Universidade Brasileira até os anos 90, apesar de certas oscilações, tinha não só a hegemonia do setor público como também tinha uma orientação geral voltada, predominantemente, para a pesquisa básica. A partir dos anos 90, deslocamentos e mudanças importantes começam a atingir o perfil da universidade e educação superior em geral.

\section{A EXPANSÃO DA EDUCAÇÃO SUPERIOR}

A Universidade brasileira e a educação superior como um todo, nas últimas décadas, vem passando por deslocamentos e mudanças em sua constituição, finalidades e práticas, seja por razões exógenas como a legislação (mas não só), seja por mecanismos internos de resposta a condicionantes mais amplos (RANIERI, 2000).

Tais deslocamentos e mecanismos geram impactos não desprezíveis nas finalidades proclamadas da educação superior, especialmente na legislação, como aparato institucional de formação que se nutre do conhecimento acumulado e do conhecimento em processo de formação.

Entre tais mecanismos cai aos olhos o crescimento das instituições de ensino superior. Tal fenômeno é apontado, seja nas estatísticas oficiais (como Instituto Nacional de Estudos e Pesquisas - INEP), em inúmeras dissertações e teses, além de livros e artigos em periódicos dedicados ao assunto. A revista Avaliação contém em vários números, artigos que remetem a tal expansão, sob as mais variadas formas.

Este crescimento aponta uma extraordinária expansão do segmento privado lucrativo que, também, por sua vez, vem conhecendo migrações e deslocamentos internos, como fusões, incorporações e, em especial, por meio de um modo específico de financeirização. Ao lado da financeirização, destaca-se 
em tais instituições de ensino superior, $a$ oferta de cursos sobre a base exclusiva do ensino presencial ou a distância. A escassa pesquisa que nelas possa acontecer, está radicada ou em instituições propriamente universitárias (por imposição legal) ou em raros departamentos em que se tenha um docente que, motu próprio, desenvolva investigação.

Como se sabe 2 variáveis concorreram para tal: o acesso ampliado ao ensino médio com uma maior terminalidade e a flexibilidade trazida pelas diretrizes e bases da educação nacional, lei n. 9.394/96. Ao aspecto positivo da primeira variável, há que se analisar melhor a segunda. ${ }^{5}$ Uma flexibilidade desejável não se coaduna com insuficiência ou leniência em controles necessários. Rigorosamente, flexibilidade não significa precariedade de qualquer natureza. E é aqui que o papel das políticas de educação superior exaradas pelo executivo e o modo como o órgão normativo do sistema (CNE) interpretou a legislação conduziram a uma expansão, hoje sem controle. Na década de 90 houve uma abertura excessiva para com a expansão privada do ensino superior, apesar de haver alguns critérios gerais postos na LDB de 1996. Houve uma moderação significativa nas exigências dos processos de abertura e autorização de instituições de ensino superior, máxime, particulares. Assinale-se que, mediante decreto governamental, criou-se a figura dos centros universitários que deveriam ser centro de excelência de ensino.

E isto conduziu a uma não detectação das insuficiências e inconsistências posteriormente verificadas. Basta verificar se houve, no período, descredenciamentos proporcionais aos resultados negativos das avaliações. O descredenciamento é ato previsto pela $\mathrm{LDB}$, no art. 46, em razão de insuficiências contínuas.

Tome-se como referência dessa expansão um livro que, baseando em dados do INEP e, em outras fontes oficiais e próprias, nos trazem um quadro evolutivo muito significativo. Tais tabelas e gráficas, ao final deste texto, demonstram como, a partir de 1998, o salto expansivo é congruente com as políticas adotadas e com a produção autorizatária do CNE a respeito da abertura de instituições de ensino superior (NUNES, 2012).

A dinâmica oficial insinuava que haveria dois dispositivos que estabeleceriam uma espécie de controle qualitativo que redundaria no decréscimo quantitativo no caleidoscópio da expansão: a cultura da avaliação e, como consequência da publicidade dada a esta, um maior rigor no critério de escolha da parte dos demandantes.

A falta de consequências, apesar de legalmente previstas na LDB, e a limi-

5 Para um maior detalhamento da presença dos eixos da LDB: flexibilidade e avaliação ver Cury (1997). 
tação do perfil avaliativo conduziram a que o modelo de avaliação até então adotado, isto é o Exame Nacional de Cursos (vulgo Provão) passasse a ser objeto de críticas com direito a réplicas e tréplicas.

O novo governo que assumiu em 2003 vinha com a promessa de alterar a avaliação do ensino superior de modo a considerar aspectos qualitativos, sem desconsiderar a base de dados institucionais trazidos pelos relatórios de avaliações. Como se viu acima, foi instituído o SINAES, um tanto diferente do Provão, mas que, por várias mudanças, vem tomando um perfil híbrido, especialmente por retornar a um rakeamento das instituições (DIAS SOBRINHO, 2008).

No caso das instituições privadas, recorro a um estudioso do assunto para explicitar esse recorte de leitura da educação superior. A forte demanda pelo ensino superior, o recuo das políticas públicas na oferta, segundo Oliveira (2009, p. 741-742) "criou um próspero e afluente mercado, cuja faceta mais importante refere-se à penetração do capital financeiro na educação e a consequente internacionalização da oferta educacional". ${ }^{6}$

E como o Brasil não foge aos impactos desta internacionalização, especialmente em sua vertente financeira, continua o citado autor:

a atenção dos fundos de investimento voltou-se para essa área, ocasião em que foram constituídos os primeiros fundos de investimento exclusivamente direcionados à educação. Esses fundos têm condições de injetar altas quantias em empresas educacionais, ao mesmo tempo em que empreendem ou induzem processos de reestruturação das escolas nas quais investem, por meio da redução de custos, da racionalização administrativa, em suma, da "profissionalização" da gestão das instituições de ensino, numa perspectiva claramente empresarial. Essa perspectiva racionalizadora é fundamentalmente orientada para a maximização de lucros, chegando ao paroxismo em algumas situações (p. 743).

Sabe-se que a proposta de reforma universitária enviada pelo governo ao Congresso (PL n. 7200/06) e que dorme em paz nas gavetas do Legislativo com o beneplácito do Executivo, estabelece barreiras quanto à manutenção dos estabelecimentos privados de ensino superior. Assim se dá com o artigo $3^{\circ}$ e, especialmente com o $\S 4^{\circ}$ do art. $7^{\circ}$ :

6 Um órgão da imprensa, Valor Econômico, é fonte de notícias do crescimento expansivo e da penetração financeira na área. Cite-se um periódico, Isto É Dinheiro, maio de 2013, cuja matéria de capa traz dois sorridentes empresários do ramo com o título: Os Bilionários da Educação. Mais recentemente, a revista Carta Capital, maio de 2014, também traz matéria sob o título de Mercado Nota 10 em que com empurrão público, as faculdades privadas atraem investidores. 
Art. $3^{\circ} \mathrm{A}$ educação superior é bem público que cumpre sua função social por meio das atividades de ensino, pesquisa e extensão, assegurada, pelo Poder Público, a sua qualidade. ${ }^{7}$

[...]

Art. $7^{\circ}$ Poderá manter instituição de ensino superior:

I - o Poder Público; e

II - pessoa física, sociedade, associação ou fundação, com personalidade jurídica de direito privado, cuja finalidade principal seja a formação de recursos humanos ou a produção de conhecimento.

$\S 1$ o As instituições de ensino superior mantidas pelo Poder Público e vinculadas ao Ministério da Educação terão personalidade jurídica própria.

$\S 2^{\circ}$ Os atos jurídicos das instituições de ensino superior mantidas por pessoa jurídica de direito privado serão praticados por intermédio de sua mantenedora.

$\S 3^{\circ}$ Os atos constitutivos da mantenedora de instituição privada de ensino superior, bem como os demais atos e alterações que impliquem o controle de pessoal, patrimônio e capital social, serão devidamente informados ao órgão oficial competente do respectivo sistema de ensino.

$\S 4^{\circ}$ Em qualquer caso, pelo menos setenta por cento do capital votante das entidades mantenedoras de instituição de ensino superior, quando constituídas sob a forma de sociedade com finalidades lucrativas, deverá pertencer, direta ou indiretamente, a brasileiros natos ou naturalizados.

$\S 5^{\circ}$ É vedada a franquia na educação superior.

Mas esse mesmo autor, face a esse $\S 4^{\circ}$ do art. $7^{\circ}$, aponta um outro rumo que os deslocamentos vão tendo nessa área.

Mesmo que vingasse a proposta formulada pelo MEC de limitar a participação estrangeira a 30\% do capital total das escolas, isso seria contornado com a compra de ações na bolsa, onde não há limites. As tentativas de impedir a mercantilização da educação por meio de proibições legais mostram-se mais formais do que instrumento efetivo. Vide a antiga proibição das instituições educacionais auferirem lucro. É mais ou menos como proibir a circulação de uma mercadoria para a qual há demanda. A consequência é apenas o aparecimento de um mercado negro. Ou seja, viabilizam-se formas de burla ao dispositivo legal (p. 753).

A financeirização é uma espécie do gênero mercantilização. A financeirização é um diferencial do capitalismo contemporâneo no qual o capital financei-

7 A discussão sobre a universidade como bem público ou como instituição de serviço pode ser conferida em Sguissardi et al. (2004). 
ro não financia o setor produtivo, ele especula com todo o tipo de rendimentos para os rentistas, distorcendo o que deveria o ser financiamento.

Entretanto, mais do que sua transformação em mercadoria, o que estamos observando, no caso do ensino superior, é um processo intenso de concentração. Assim, é possível falarmos, também, em processo de oligopolização. Ou seja, o número de fornecedores tende a se concentrar ainda mais nos próximos anos e uma fatia significativa do mercado tende a ficar com os maiores grupos. Mantidas as condições atuais de sustentação exclusivamente por mensalidades, poucos serão os que conseguirão ocupar nichos específicos do mercado sem ser acossados pelas instituições maiores (p. 754).

E continua apontando aspectos novos nesses movimentos internos ao desenho do ensino superior:

$\mathrm{Na}$ medida em que as tentativas de limitar sua expansão, pela via da regulação ou restrições legais, me parecem fadadas ao fracasso, ainda que devam ser implementadas como forma de preservar condições mínimas de funcionamento que não corrompam e desmoralizem completamente a natureza da atividade educativa na sociedade, entendo que só é possível limitar sua expansão a partir de uma ampliação da oferta pública, de modo a atender a parcelas substantivas da população e criar alternativas de atendimento em massa. Isto implica, portanto, um enfrentamento da complexa questão do equacionamento das condições de oferta pública, que abrange desde aspectos relativos à eficiência da gestão no âmbito dos serviços públicos, à diferenciação dos modelos de organização do ensino superior, à utilização das novas tecnologias da informação e as condições de financiamento do ensino superior. Para tal, será necessário implementar resoluta política de valorização do setor público. Entretanto, transformar tal formulação em política prática pressupõe superar desafios complexos, que se iniciam com a construção de uma estratégia comum de valorização do público. O problema é que longe estamos de conseguir estabelecer tal estratégia (p. 754-755).

Dada a demanda existente por ensino superior, o governo Lula, até por promessa de campanha, buscou meios de ampliar a entrada de estudantes no ensino superior.

É nesse contexto que se pode ter uma leitura do Programa Universidade para Todos (PROUNI). O Programa Universidade para Todos (PROUNI) concede bolsas integrais ou parciais para estudantes das instituições de ensino superior privadas em vagas para estudantes selecionados pelo Exame Nacional do Ensino Médio (ENEM). Em contrapartida, tais instituições ficam isentas 
de determinados impostos. ${ }^{8} \mathrm{O}$ PROUNI é um dispositivo legal estabelecido pela Lei n. 11.096/2005. E aí, apesar de seus méritos aferidos pelos indivíduos que dele se valem, ele se enquadra nesse quadro de reforço da oligopolização (FACEIRA, 2009; CATANI; HEY; GILIOLI, 2006).

Ao lado deste programa, o governo federal, mediante o Decreto $\mathrm{n}$. 6096/2007, constante do Plano de Desenvolvimento da Educação (PDE), instituiu o Programa de Apoio a Planos de Reestruturação e Expansão das Universidades Federais (REUNI) vem expandindo da rede pública federal. Também faz parte destas iniciativas a Universidade Aberta do Brasil, instituída pelo Decreto n. 5800/2006. Trata-se de um programa busca ampliar e interiorizar a oferta de cursos e programas de educação superior, por meio da educação a distância. A prioridade é oferecer formação inicial a professores em efetivo exercício na educação básica pública, porém ainda sem graduação, além de formação continuada àqueles já graduados. Também pretende ofertar cursos a dirigentes, gestores e outros profissionais da educação básica da rede pública. Outro objetivo do programa é reduzir as desigualdades na oferta de ensino superior e desenvolver um amplo sistema nacional de educação superior a distância. Tais ações se constituíram como os novos mecanismos de abertura de vagas.

Outro ponto a se destacar no atual desenho do ensino superior privado é a presença de determinantes de uma competição própria do sistema contratual de mercado entre as instituições e o apontamento aos estudantes de que nelas se busca e se dá uma aplicação pragmática dos conhecimentos.

Como diz Brunner (2014):

Não há praticamente nenhuma análise da educação superior em nível global e das diferentes regiões e países do mundo na qual a análise do "estado da arte" não comece mencionando processos de 'mercadização' e privatização, de comercialização e 'managerismo', de empresarialização e 'comodificação'. Isso reflete a importância alcançada por esses fenômenos, independentemente da nossa opinião sobre eles (p. 15).

Ao lado disso, a financeirização que envolve os grandes aglomerados institucionais formados por fusões, se vê associada à globalização que atinge todos os setores da vida contemporânea. ${ }^{9}$

8 A lei que o criou, inicialmente exigia uma contrapartida das instituições privadas sem fins lucrativos para a isenção fiscal de que gozam pelo art. 150 da Constituição atual. Tal isenção advém desde 1934. $\mathrm{E}$ tal franquia foi estendida às instituições com fins lucrativos que aderirem ao PROUNI.

9 Sobre a influência de organismos multilaterais na educação brasileira ver Mello (2012). 
Aqui não há outro caminho: trata-se de ampliar o segmento público (estadual e federal), mesmo que essa ampliação não se faça necessariamente pela ereção de universidades. Uma federação de faculdades públicas pode muito bem atender à diversidade regional pela qualidade de seu ensino e pela riqueza de recursos didáticos em suas instalações como bibliotecas atualizadas, laboratórios de ensino, assinaturas de revistas científicas e, mais do que tudo, professores qualificados.

Contudo, há um aspecto interno a essa expansão que vem chamando à atenção dos analistas do ensino superior. Trata-se de um movimento por dentro das instituições de ensino superior no que se refere à relação conhecimento e formação nas públicas e no que se refere ao crescimento nas instituições privadas.

Nas instituições públicas, especialmente aquelas sob a forma de universidades e que possuem um quadro de pós-graduação com pesquisa avançada, em especial nas áreas de exatas e tecnológicas, percebe-se mudanças que vão no sentido de um empreendedorismo acadêmico, ou, nos termos de Sheila Slaughter, de um capitalismo acadêmico. ${ }^{10} \mathrm{~A}$ urgência em articular a universidade com a transferência de conhecimentos inovadores para o setor produtivo por meio de escritórios especializados em tecnologia indica uma busca alternativa de fonte de recursos que não a advinda dos fundos públicos. Tal deslocamento implicaria na redefinição do conhecimento de modo que este se intencionaria mais em função do mercado do que para os interesses mais amplos sediados na pesquisa básica e no conhecimento crítico- contextual. Diz Brunner (2014):

Os analistas costumam interpretar essas mudanças, no caso das universidades estatais, como fenômenos de privatização e de adoção de um estilo gerencial centrado em valores de eficiência e em critérios comerciais, o que seria profundamente contrário às tradições colegiais e aos valores de altruísmo universal que haviam marcado o nascimento da universidade pública, pelo menos - é o que se afirma - sob a inspiração do modelo Humboldtiano (p. 17).

Com isto, há uma grande diminuição do papel central do Estado em relação à organização do ensino superior até porque o próprio Estado vem se redefinindo nesta relação com a educação superior, em especial, a estatal. A ênfase

10 A revista Avaliação, em seu v. 15 de 2010, traz uma resenha feita por Milena Pavan Serafim a respeito do livro de Slaughter e Rhoades, 2004. Destacando que o livro traz uma teoria do capitalismo acadêmico, a resenhista assinala que a abordagem do livro centra sua análise na linha nebulosa que separa mercado, Estado e educação superior...em cujo fio as IES norte-americanas se esforçam em desenvolver, mercantilizar e vender produtos de pesquisa, serviços educacionais e bens de consumo no mercado privado. 
se desloca para a prestação de contas do financiamento repassado, para o estabelecimento de metas mensuráveis a serem alcançadas, para a montagem de avaliações de larga escala e para o resultado das avaliações, tudo seguido de relatórios e mais relatórios. ${ }^{11}$ Outro ponto de modificação é a ênfase em vista da busca de fontes de financiamento fora do orçamento estatal. Como decorrência de tais mudanças, a administração geral e específica das instituições superiores públicas perseguem o modelo de eficiência cujo padrão provém da administração gerencial como racionalização, terceirização, entre outros.

Neste sentido, observa-se que há um deslocamento do papel do Estado em direção à sociedade civil como em uma espécie de terceirização. Como decorrência tendem a surgir, no espaço público, as características de gestão próprias do sistema contratual de mercado, entre as quais a competição e a aplicação imediata dos conhecimentos.

Vale dizer, há um deslocamento do modelo humboldtiano para um modelo de universidade pragmática que, se de um lado recusa o verbalismo, por outro lado se encaminha para a pesquisa e o ensino aplicados à tecnologia e à indústria (BRUNNER, 2014).

Este caminho, se tendencial, torna a formação e o conhecimento mais próximos de uma concepção pragmática e conduz a uma redução tanto de aspectos concernentes à pesquisa básica, quanto de uma visão também reduzida do papel da universidade, frente ao quadro holístico posto no artigo 43 (finalidades da educação superior) da lei de diretrizes e bases da educação nacional. ${ }^{12}$

Estaria o sistema público de educação superior cedendo à tentação de um capitalismo acadêmico ?

O artigo supra citado da LDB postula, sim, uma qualificação profissional sólida que possa se efetivar em uma inserção no mundo do trabalho contemporâneo. Mas, ao mesmo tempo, incita à superação de um pragmatismo cognoscitivo de modo que desta qualificação não escape a formação para o exercício de uma cidadania consciente da qual fazem parte a arte, a cultura e a participação crítica na vida social.

11 Um aspecto decorrente de tais exigências é a intensificação do trabalho docente (SGUISSARDI, 2009).

12 Sobre a resistência a um modelo pragmático de universidade e do critério de avaliação que a rege ver Palharini (2004). 


\section{REFERÊNCIAS}

ARAÚJO, José Carlos Souza. A universidade iluminista (1798-1921), de Kant a Max Scheller. Brasília: LiberLivro, 2011. v. 1.

AVALIAÇÃO: Revista da Avaliação da Educação Superior. Campinas, SP: RAIES; Sorocaba, SP: UNISO, v. 13, n. 1, mar. 2008.

BRUNNER, José Joaquín. A ideia da universidade pública: narrações contrastantes. Ensaio, Rio de Janeiro, n. 82, p. 11-30, jan/mar, 2014.

CATANI, A. M.; HEY, A. P; GILIOLI, R. S. P. PROUNI: democratização de acesso às instituições de ensino superior ? Educar em Revista, Curitiba, n. 28, p. 125-140, 2006.

CUNHA, Luiz Antônio. A universidade reformanda: o golpe de 1964 e a modernização do ensino superior. Rio de Janeiro: Francisco Alves, 1988.

CURY, Carlos Roberto Jamil. A desoficialização do ensino no Brasil: a reforma rivadávia. Educ. Soc., Campinas, v. 30, n. 108, p. 717-738, out. 2009.

CURY, Carlos Roberto Jamil. Quadragésimo ano do parecer n. 977/65. Revista Brasileira de Educação, Rio de Janeiro, n. 30, p. 7-20, set./dez. 2005.

CURY, Carlos Roberto Jamil. A evolução da educação superior no Brasil: a participação do setor público e da iniciativa privada. Revista Brasileira de Política e Administração da Educação, Brasília, v. 13, n. 1, p. 39-69 , jan/ jun. 1998.

CURY, Carlos Roberto Jamil. Leis Nacionais da Educação: uma conversa antiga. In: CURY, Carlos Roberto Jamil. Medo à liberdade e compromisso democrático: LDB e Plano Nacional de Educação. São Paulo : Editora do Brasil, 1997.

DIAS SOBRINHO, José. Qualidade, avaliação: do SINAES aos índices. Avaliação, Campinas; Sorocaba, v. 13, n. 3, p. 817-825, 2008.

FACEIRA, Lobélia da Silva. O ProUni como política pública em suas instâncias macroestruturais, meso-institucionais e microssociais: 
pesquisa sobre a sua implementação pelo MEC e por duas Universidades na Região Metropolitana do Rio. Tese (Doutorado em Educação) - Programa de Pós-Graduação de Educação, Pontifícia Universidade Católica do Rio de Janeiro, Rio de Janeiro, 2009.

MELLO, Hivy Damásio Araújo. O Banco Mundial e a educação no Brasil: convergências em torno de uma agenda global. Tese (Doutorado em Sociologia) - Universidade Estadual de Campinas, Campinas, 2012.

NUNES, Edson de Oliveira. Educação superior no Brasil: estudos, debates, controvérsias. Rio de Janeiro: Garamond, 2012.

OLIVEIRA, Romualdo Portela de. A transformação da educação em mercadoria. Educação e Sociedade, Campinas, n. 108, p. 739-760, 2009.

PALHARINI, Francisco de Assis. Avaliação: polo de resistência da avaliação institucional, autônoma e democrática. In: FÁVERO, Maria de Lourdes de Albuquerque; MANCEBO, Deise (Org.). Universidade: políticas, avaliação e trabalho docente. São Paulo: Cortez, 2004.

RANIERI, Nina Beatriz. Educação superior, diretrizes e estado: na lei de diretrizes e bases (lei n. 9.394/96). São Paulo: EDUSP/FAPESP, 2000.

RISTOFF, D. I. Princípios do programa de avaliação institucional. Avaliação, Campinas, v. 1, n. 1, p. 47-53, jul. 1996.

ROSSATO, Ermélio. Modelos da universidade brasileira (1920 -1968). Santa Maria: Biblos, 2008

SLAUGHTER, Sheila; RHOADES, Gary. Academic Capitalism and the new economy: markets, state and higher education. Baltimore: The Johns Hopkins University Press, 2004. Resenha de: SERAFIM, Milena Pavan. Avaliação, Capmpinas; Sorocaba, v. 15, n. 1, mar. 2010.

SGUISSARDI, Valdemar et al. Universidade: reforma e/ou rendição ao mercado? mercantilização do conhecimento e deserção do estado. Educação e Sociedade, Campinas, v. 25, n. 88 especial, Editorial, oct. 2004.

SGUISSARDI, Valdemar; SILVA JÚNIOR, J. R. Trabalho intensificado nas federais: pós-graduação e produtivismo acadêmico. São Paulo: Xamã, 2009. 


\section{Tabelas e Gráficos}

Evolução dos números de matrículas em estabelecimentos públicos e privados no ensino superior brasileiro (1933 - 2010)

\begin{tabular}{rrrrrr}
\hline \multirow{2}{*}{ Ano } & \multicolumn{2}{c}{ Público } & \multicolumn{2}{c}{ Privado } & \\
\cline { 2 - 5 } & Número & $\%$ & Número & $\%$ & \multicolumn{1}{c}{ Total } \\
\hline 1933 & 18.986 & $56.3 \%$ & 14.737 & $43.7 \%$ & 33.723 \\
1945 & 21.307 & $51.6 \%$ & 19.968 & $48.4 \%$ & 41.275 \\
1960 & 59.624 & $58.6 \%$ & 42.067 & $41.4 \%$ & 101.691 \\
1970 & 210.613 & $49.5 \%$ & 214.865 & $50.5 \%$ & 425.478 \\
1980 & 492.232 & $35.7 \%$ & 885.054 & $64.3 \%$ & 1.377 .286 \\
1990 & 578.625 & $37.6 \%$ & 961.455 & $62.4 \%$ & 1.540 .080 \\
2000 & 887.026 & $33.0 \%$ & 1.807 .219 & $67.0 \%$ & 2.694 .245 \\
2001 & 944.584 & $31.1 \%$ & 2.091 .529 & $68.9 \%$ & $3.036 .113^{*}$ \\
2002 & 1.085 .977 & $30.8 \%$ & 2.434 .650 & $69.2 \%$ & 3.520 .627 \\
2003 & 1.176 .174 & $29.9 \%$ & 2.760 .759 & $70.1 \%$ & 3.936 .933 \\
2004 & 1.214 .317 & $28.8 \%$ & 3.009 .027 & $71.2 \%$ & 4.223 .344 \\
2005 & 1.246 .704 & $27.3 \%$ & 3.321 .094 & $72.7 \%$ & 4.567 .798 \\
2006 & 1.251 .365 & $25.6 \%$ & 3.632 .487 & $74.4 \%$ & 4.883 .852 \\
2007 & 1.335 .177 & $25.4 \%$ & 3.914 .970 & $74.6 \%$ & 5.250 .147 \\
2008 & 1.552 .953 & $26.7 \%$ & 4.255 .064 & $73.3 \%$ & 5.808 .017 \\
2009 & 1.523 .864 & $25.6 \%$ & 4.430 .157 & $74.4 \%$ & 5.954 .021 \\
2010 & 1.643 .298 & $25.8 \%$ & 4.736 .001 & $74.2 \%$ & 6.379 .299 \\
\hline
\end{tabular}

Fonte: Elaborado com base nos dados do INEP (2010). $\left(^{*}\right)$ incluindo EAD.

Produção do CFE entre 1962 a 1994 (somente pareceres, exclusive diligências, indicações, resoluções e portarias)

\begin{tabular}{|c|c|c|c|c|c|c|c|c|c|c|}
\hline 1962 & 1963 & 1964 & 1965 & 1966 & 1967 & 1968 & 1969 & 1970 & 1971 & 1972 \\
\hline 339 & 359 & 371 & 1.017 & 642 & 501 & 912 & 975 & 945 & 928 & 1.542 \\
\hline 1973 & 1974 & 1975 & 1976 & 1977 & 1978 & 1979 & 1980 & 1981 & 1982 & 1983 \\
\hline 2.795 & 4.552 & 5.312 & 4.735 & 3.895 & 7.887 & 1.739 & 1.422 & 916 & 659 & 669 \\
\hline 1984 & 1985 & 1986 & 1987 & 1988 & 1989 & 1990 & 1991 & 1992 & 1993 & 1994 \\
\hline 879 & 901 & 892 & 1.176 & 1.385 & 1.171 & 1.002 & 767 & 750 & 912 & $915^{\star}$ \\
\hline
\end{tabular}

Índice Numérico da Revista Documenta. Cortesia da Biblioteca do CNE.

* até outubro de 1994.

Fonte: NUNES, Edson de Oliveira. Educação superior no Brasil: estudos, debates, controvérsias. Rio de Janeiro: Garamond, 2012. p. 362. 
Produção do CFE (pareceres) - 1962 - 1994

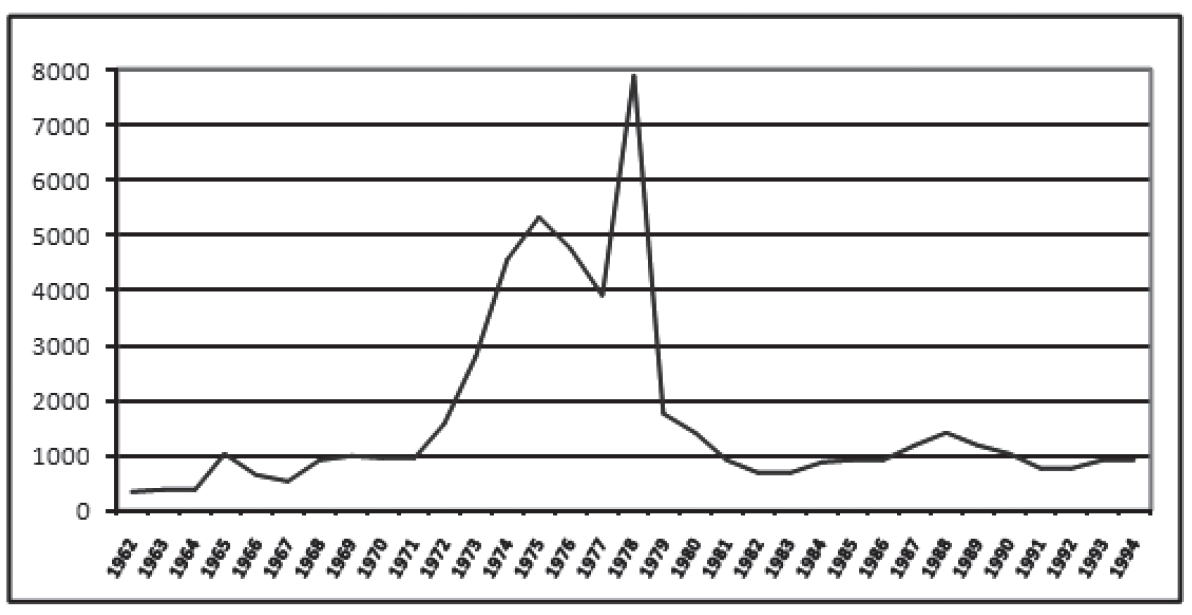

Índice Numérico da revista Documenta. Cortesia da Biblioteca do CNE.

Fonte: NUNES, Edson de Oliveira. Educação superior no Brasil: estudos, debates, controvérsias. Rio de Janeiro: Garamond, 2012. p. 362.

Número de pareceres do CNE segundo a origem - 1996 a 2011

\begin{tabular}{|c|c|c|c|c|c|c|c|c|c|c|c|c|c|c|c|c|}
\hline \multirow{2}{*}{ 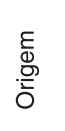 } & \multicolumn{16}{|c|}{1996 a junho de 2011} \\
\hline & $\begin{array}{l}\text { ᄋ } \\
\stackrel{-}{\circ}\end{array}$ & 욤 & $\begin{array}{l}\infty \\
\stackrel{\infty}{\sigma} \\
+\end{array}$ & ஓ্ & ঃ & চ্ণ & ণ্ণ & ঠి & ষ্ণ & 유 & ஜ̊ & ণ্ণ & $\begin{array}{l}\infty \\
\stackrel{\sim}{\sim}\end{array}$ & 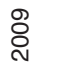 & 응 & స్ \\
\hline CEB & 5 & 19 & 24 & 17 & 28 & 36 & 42 & 38 & 40 & 32 & 45 & 26 & 28 & 23 & 17 & 8 \\
\hline CES & 361 & 3722 & 1581 & 1282 & 1739 & 1336 & 459 & 360 & 392 & 479 & 296 & 282 & 288 & 390 & 270 & 210 \\
\hline $\mathrm{CP}$ & 4 & 26 & 102 & 121 & 131 & 33 & 31 & 20 & 7 & 5 & 13 & 9 & 8 & 33 & 13 & 4 \\
\hline Total & 370 & 3767 & 1707 & 1420 & 1898 & 1405 & 532 & 418 & 439 & 516 & 354 & 317 & 324 & 446 & 300 & 222 \\
\hline
\end{tabular}

Fonte: CNE. Relatórios de Gestão 1996 a 2010. Dados de 2011 (até junho): site do CNE. 
Deliberações do CNE entre 1996 e junho de 2011 (\%)

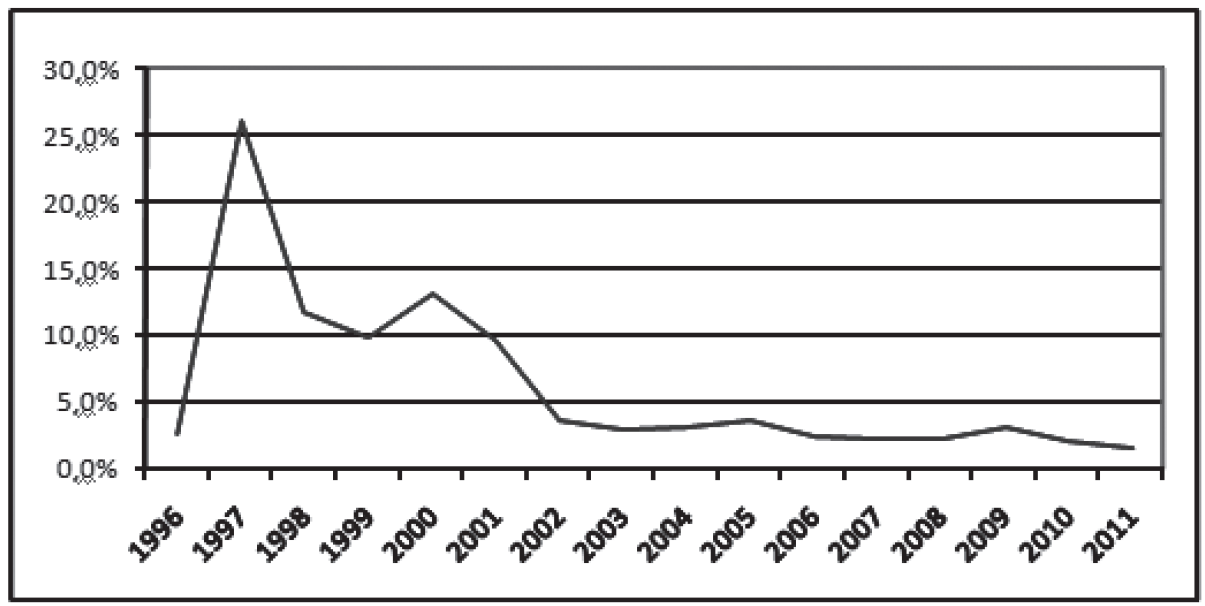

Fonte: NUNES, Edson de Oliveira. Educação superior no Brasil: estudos, debates, controvérsias. Rio de Janeiro: Garamond, 2012. p. 361.

Evolução das matrículas em cursos de graduação presenciais por categoria administrativa - Brasil (1991 - 2010)

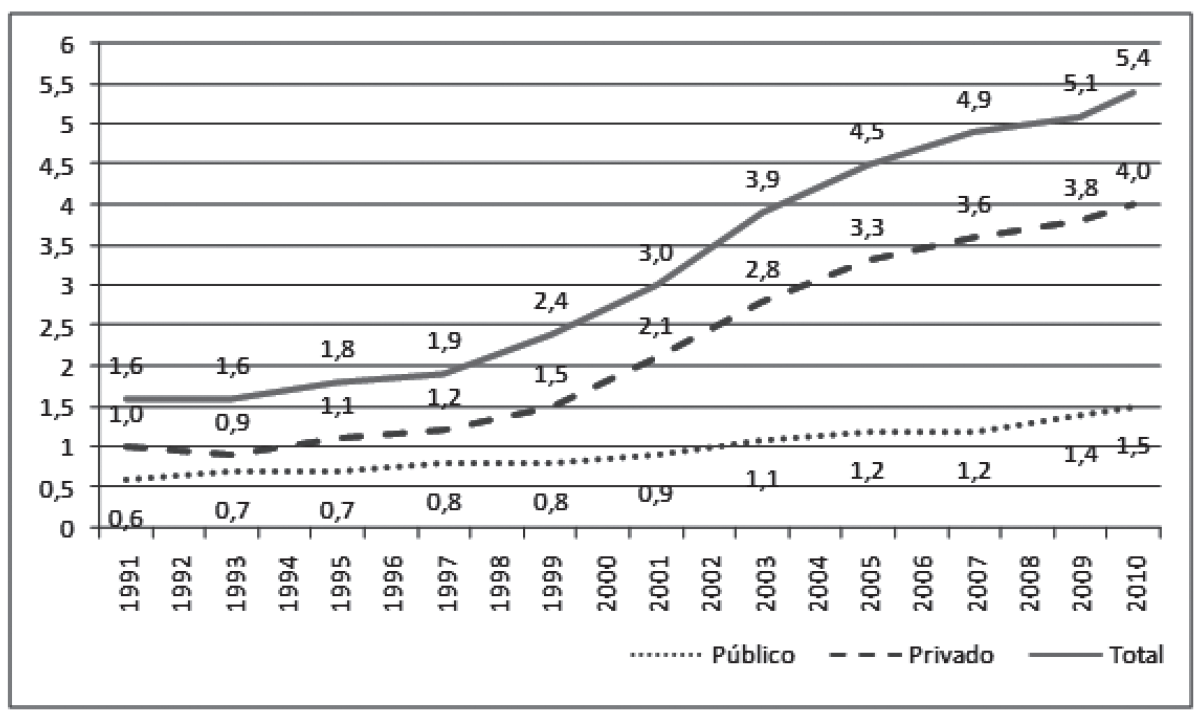

Fonte: NUNES, Edson de Oliveira. Educação superior no Brasil: estudos, debates, controvérsias. Rio de Janeiro: Garamond, 2012. p. 361. 